\title{
Effect of Protein 'Hair Straightener" on Hair Shaft by Scanning Electron Microscopy
}

\author{
A.A.Saleh, N.G.Elhefnawy, M.S.Hussein and W.H.Ali \\ Venereology \& Andrology Dept., Faculty of Medicine, Benha Univ., Benha, Egypt \\ E-Mail: M.Mahdy@gmail.com
}

\begin{abstract}
Background:. Permanent hair straightening or waving requires changes in hair disulfide bonds. We aimed in this study to assess the role of scanning electron microscopy in hair shaft changes for female volunteers who frequently use hair treatment procedures such as straightening. Subjects and methods: Our study included 70 female. Control group: 15 females. Study group: thirty five (35 females) females used straightener. Study group: twenty (20) females used dyeScanning electron microscopy: It had been used to assess the hair shaft condition in patients and two hair samples had been collected from patients group before and after using hair straightener. Results; In group A: hair straightener, there was a statistically significant difference regarding scanning electronic microscope findings before and after treatment (P-value $<0.001$ ), before treatment $51 \%$ classified as group 0 , while after treatment $31 \%$ classified as Grade II. In group B: hair dye, there was no statistically significant difference regarding EMS findings before and after treatment $(\mathrm{P}=0.966)$. before treatment, $43.64 \%$ were grade 0 , while after treatment $25.45 \%$ were Grade II. While the overall $\mathrm{P}$ value before and after treatment was $(\mathrm{P}<0.001)$. Conclusion: EMS is a useful tool in assessing hair changes related to use of chemical agents.
\end{abstract}

\section{Introduction}

Hair is a defining element of our physical appearance with significant psychological and social impacts in our daily life. Everyone within any society has an abstract, unique and innate idea of beauty. As hair is one of the physical features which are easier to modify in terms of length, color or shape, the pursuit of the desired and idealized hairstyle to achieve beauty drives many consumers and feeds a vast global cosmetic industry. Each individual is unique regarding hair growth rate, size and shape, but there are general properties of the hair fiber thatcan be grouped according to the ethnic background [1].

Hair style is a human characteristic that may represent aspects of identity, ethnic group and health. Hair is one of the physical features easier to modify. Hair care industry has developed plenty products to provide beauty and modify some hair characteristics. Hair waving and straightening are procedures that change hair physical appearance, regarding shape, in a durable way [2].

There is an essential difference between these procedures and hair setting. Temporary straightening or waving requires physicochemical techniques such as dryer, flat iron, hot comb and lasts only until the next wash. Hair has to be wetted to break the hydrogen bonds of keratin, allowing a temporary opening of its original structure. Fast hair drying and mechanical aid maintain the flat or waved strand of the hair. Consequently, the new shape is moisture sensitive. Permanent hair straightening or waving requires changes in hair disulfide bonds [3].

These techniques involve manipulation of the physicochemical interactions that stabilize the keratin structure, through keratin softening, molding to the intended shape and providing a new geometry. This occurs through breakage of disulfide bonds between keratin filaments and their posterior rearrangement into the desired shape, affecting the structural integrity and hair cystine content [4].
Keratin treatment encountered several adverse events and undesirable outcomes such as burning eyes, strong smell, dermatitis, alopecia and burning mouth and nose [5].

We aimed to assess the role of scanning electron microscopy in hair shaft changes for female volunteers who frequently use hair treatment procedures such as straightening.

\section{Patient and method}

The study will include 50 female volunteers aged from 18- 45 years who will divide as follow:

A. Control group: fifteen (15 females) normal volunteers who didn't use straightener before.

B. Study group: thirty five (35 females) females used straightener.

Study group: twenty (20) females used dye.

All patients with any of the following condition will be excluded from the study

- Pregnancy.

- Lactation.

- Liver, kidney disease.

- Fiver.

- Thyroid.

- Chemotherapy. All patients in this study to be subjected to the following

A. Throughout personal history taking.

B. General and local examination.

C. Instruments will be used in the study.

\section{Scanning electron microscopy}

It will be used to assess the hair shaft condition in patients and two hair samples will be collected from patients group before and after using hair straightener.

- Hair samples will be collected from all patients and analyzed after cutting from the hair root. After naked eye examination of the hair shafts.

- Hair samples will attached to a double coated carbon conductive tape, mounted on metal aluminum stubs, 
and sputter coated under high vacuum with the LEICA EM SCD 500 sputter coating machine using platinum as a metal target (10-20 nm thickness). Multiple sections of each shaft were scanned to ensure that changes seen were uniform and not isolated.

\section{Results}

Our study included 70 female volunteers aged from 18- 45 years who will divide into 1 control and 2 studied groups:

A. Control group: fifteen (15 females) normal volunteers who didn't use straightener before.

B. Study group: thirty five (35 females) females used straightener. Study group: twenty (20) females used dye.

The damage that occurs as a result of the use of hair straightener begins from the outer layer of the hair shaft ( cuticle ) and extends to inner layers ( cortex ) which leads to the irregularity of cuticle and develops into very large damage until the distraction of the inner layer and the hair shaft his broken.

As regarding scanning electronic microscope finding in Group A according previous hair straightener apply. There was a statistically significant difference regarding EMS findings before and after treatment $(\mathrm{P}<0.001)$.

Also in analyzing scanning electronic microscope finding in Group B to previous dye apply. There was a statistically significant difference regarding EMS findings before and after treatment $(\mathrm{P}<0.014)$.

In Comparison between the three studied groups according to age, There was no statistically significant difference between them.
While Comparison between the two studied groups according to age and before applying treatment. In Group A, There was no statistically significant difference $(\mathrm{P}=0.839)$, while in Group $\mathrm{B}$ there was a statistically significant difference $(\mathrm{P}<0.001)$.

Also Comparison between the two studied groups according to age and after applying treatment, in Group A, there was no statistically significant difference $(\mathrm{P}=0.074)$, in Group $\mathrm{B}$, there was a statistically significant difference $(\mathrm{P}=0.013)$.

These results showed that, the use of hair straightener leads to very significant damage to the layers of hair especially if the individual is frequent compared to using the dye that is considered less harmful.

As regarding Compression between the two studied groups according to previous treatment. In group A: hair straightener, $57.14 \%$ of them experienced previous treatments. While in in group B: hair dye, $50 \%$ of them experienced previous treatment. There was no statistically significant difference between both groups regarding previous treatments $(\mathrm{P}=0.609)$.

As regarding Compression between the two studied groups according to scanning electronic microscope finding of hair. In group A: hair straightener, there was a statistically significant difference regarding EMS findings before and after treatment (P-value <0.001), before $\mathrm{ttt} 51 \%$ classified as group 0 , while after treatment $31 \%$ classified as Grade II. In group B: hair dye, there was no statistically significant difference regarding EMS findings before and after treatment $(\mathrm{P}=0.966)$. before $\mathrm{ttt}, 43.64 \%$ were grade 0 , while after $\mathrm{tt}$ $25.45 \%$ were Grade II. While the overall $\mathrm{P}$ value before and after treatment was $(\mathrm{P}<0.001)$.

Table (1) Compression between the two studied groups according to scanning electronic microscope finding of hair.

\begin{tabular}{|c|c|c|c|c|c|c|c|c|c|}
\hline \multirow{2}{*}{\multicolumn{2}{|c|}{$\begin{array}{l}\text { Scanning electronic microscope finding of } \\
\text { hair }\end{array}$}} & \multicolumn{6}{|c|}{ Groups } & \multirow{2}{*}{\multicolumn{2}{|c|}{ Chi-Square }} \\
\hline & & \multicolumn{2}{|c|}{ GroupA } & \multicolumn{2}{|c|}{ Group B } & \multicolumn{2}{|c|}{ Total } & & \\
\hline & & $\mathbf{N}$ & $\%$ & $\mathbf{N}$ & $\%$ & $\mathbf{N}$ & $\%$ & $\mathbf{X}^{2}$ & P-value \\
\hline \multirow{5}{*}{ Before } & Grade 0 & $\begin{array}{l}1 \\
8\end{array}$ & 51.43 & 6 & 30.00 & 24 & 43.64 & \multirow{5}{*}{6.473} & \multirow{5}{*}{0.167} \\
\hline & Grade I & $\begin{array}{l}1 \\
2\end{array}$ & 34.29 & 5 & 25.00 & 17 & 30.91 & & \\
\hline & Grade II & 2 & 5.71 & 4 & 20.00 & 6 & 10.91 & & \\
\hline & Grade III & 2 & 5.71 & 3 & 15.00 & 5 & 9.09 & & \\
\hline & Grade IV & 1 & 2.86 & 2 & 10.00 & 3 & 5.45 & & \\
\hline \multirow{5}{*}{ After } & Grade 0 & 2 & 5.71 & 5 & 25.00 & 7 & 12.73 & \multirow{5}{*}{8.598} & \multirow{5}{*}{0.072} \\
\hline & Grade I & 3 & 8.57 & 5 & 25.00 & 8 & 14.55 & & \\
\hline & Grade II & $\begin{array}{l}1 \\
1\end{array}$ & 31.43 & 3 & 15.00 & 14 & 25.45 & & \\
\hline & Grade III & 9 & 25.71 & 4 & 20.00 & 13 & 23.64 & & \\
\hline & Grade IV & $\begin{array}{l}1 \\
0\end{array}$ & 28.57 & 3 & 15.00 & 13 & 23.64 & & \\
\hline Chi-Square & $\begin{array}{c}X^{2} \\
\text { P-value }\end{array}$ & \multicolumn{2}{|c|}{$\begin{array}{c}36.249 \\
<0.001^{*}\end{array}$} & \multicolumn{2}{|c|}{$\begin{array}{l}0.577 \\
0.966\end{array}$} & \multicolumn{2}{|c|}{$\begin{array}{l}25.568 \\
<0.001 *\end{array}$} & & \\
\hline
\end{tabular}


Table (2) Scanning electronic microscope finding in Group A according previous hair straightener apply.

\begin{tabular}{|c|c|c|c|c|c|c|c|c|c|}
\hline \multirow{3}{*}{ Hair Group A } & & \multicolumn{6}{|c|}{ Previous treatment } & \multirow{2}{*}{\multicolumn{2}{|c|}{ Chi-Square }} \\
\hline & & \multicolumn{2}{|c|}{ Negative } & \multicolumn{2}{|c|}{ Positive } & \multicolumn{2}{|c|}{ Total } & & \\
\hline & & $\mathbf{N}$ & $\%$ & $\mathbf{N}$ & $\%$ & $\mathbf{N}$ & $\%$ & $\mathbf{X}^{2}$ & P-value \\
\hline \multirow{5}{*}{ Before } & Grade 0 & 15 & 75.00 & 3 & 20.00 & 18 & 51.43 & & \\
\hline & Grade I & 5 & 25.00 & 7 & 46.67 & 12 & 34.29 & & \\
\hline & Grade II & 0 & 0.00 & 2 & 13.33 & 2 & 5.71 & 12.882 & $0.012 *$ \\
\hline & Grade III & 0 & 0.00 & 2 & 13.33 & 2 & 5.71 & & \\
\hline & Grade IV & 0 & 0.00 & 1 & 6.67 & 1 & 2.86 & & \\
\hline \multirow{5}{*}{ After } & Grade 0 & 2 & 10.00 & 0 & 0.00 & 2 & 5.71 & & \\
\hline & Grade I & 3 & 15.00 & 0 & 0.00 & 3 & 8.57 & & \\
\hline & Grade II & 11 & 55.00 & 0 & 0.00 & 11 & 31.43 & 25.926 & $<0.001 *$ \\
\hline & Grade III & 4 & 20.00 & 5 & 33.33 & 9 & 25.71 & & \\
\hline & Grade IV & 0 & 0.00 & 10 & 66.67 & 10 & 28.57 & & \\
\hline \multirow{2}{*}{ Chi-Square } & $X^{2}$ & \multirow{2}{*}{\multicolumn{2}{|c|}{$\begin{array}{c}25.441 \\
<0.001 *\end{array}$}} & \multirow{2}{*}{\multicolumn{2}{|c|}{$\begin{array}{c}20.649 \\
<0.001 *\end{array}$}} & \multirow{2}{*}{\multicolumn{2}{|c|}{$\begin{array}{l}36.249 \\
<0.001 *\end{array}$}} & & \\
\hline & P-value & & & & & & & & \\
\hline
\end{tabular}

Table (3) Scanning electronic microscope finding in Group B to previous dye apply.

\begin{tabular}{|c|c|c|c|c|c|c|c|c|c|}
\hline \multirow{2}{*}{\multicolumn{2}{|c|}{ Hair Group B }} & \multicolumn{6}{|c|}{ Previous treatment } & \multirow{2}{*}{\multicolumn{2}{|c|}{ Chi-Square }} \\
\hline & & \multicolumn{2}{|c|}{ Negative } & \multicolumn{2}{|c|}{ Positive } & \multicolumn{2}{|c|}{ Total } & & \\
\hline & & $\mathbf{N}$ & $\%$ & $\mathbf{N}$ & $\%$ & $\mathbf{N}$ & $\%$ & $\mathbf{X}^{2}$ & P-value \\
\hline \multirow{5}{*}{ Before } & Grade 0 & 6 & 60.00 & 0 & 0.00 & 6 & 30.00 & \multirow{5}{*}{16.800} & \multirow{5}{*}{$0.002 *$} \\
\hline & Grade I & 4 & 40.00 & 1 & 10.00 & 5 & 25.00 & & \\
\hline & Grade II & 0 & 0.00 & 4 & 40.00 & 4 & 20.00 & & \\
\hline & Grade III & 0 & 0.00 & 3 & 30.00 & 3 & 15.00 & & \\
\hline & Grade IV & 0 & 0.00 & 2 & 20.00 & 2 & 10.00 & & \\
\hline \multirow{5}{*}{ After } & Grade 0 & 5 & 50.00 & 0 & 0.00 & 5 & 25.00 & \multirow{5}{*}{12.533} & \multirow{5}{*}{$0.014^{*}$} \\
\hline & Grade I & 3 & 30.00 & 2 & 20.00 & 5 & 25.00 & & \\
\hline & Grade II & 2 & 20.00 & 1 & 10.00 & 3 & 15.00 & & \\
\hline & Grade III & 0 & 0.00 & 4 & 40.00 & 4 & 20.00 & & \\
\hline & Grade IV & 0 & 0.00 & 3 & 30.00 & 3 & 15.00 & & \\
\hline Chi- & $\mathrm{X}^{2}$ & \multicolumn{2}{|c|}{2.234} & \multicolumn{2}{|r|}{2.476} & \multicolumn{2}{|c|}{0.577} & & \\
\hline Square & $\mathrm{P}$-value & \multicolumn{2}{|c|}{0.327} & \multicolumn{2}{|c|}{0.480} & \multicolumn{2}{|c|}{0.966} & & \\
\hline
\end{tabular}

Table (4) Comparison between the two studied groups according to age and before applying treatment.

\begin{tabular}{|c|c|c|c|c|c|c|c|}
\hline \multirow{3}{*}{ Hair Before } & & \multicolumn{6}{|c|}{ Age } \\
\hline & & \multicolumn{3}{|c|}{ Group A } & \multicolumn{3}{|c|}{ Group B } \\
\hline & & Mean & \pm & SD & Mean & \pm & SD \\
\hline Grade 0 & & 32.222 & \pm & 4.797 & 28.667 & \pm & 3.559 \\
\hline Grade I & & 34.333 & \pm & 6.443 & 32.800 & \pm & 3.347 \\
\hline Grade II & & 35.000 & \pm & 1.414 & 41.500 & \pm & 2.380 \\
\hline Grade III & & 32.500 & \pm & 3.536 & 42.333 & \pm & 2.517 \\
\hline Grade IV & & 34.000 & \pm & 0.000 & 43.000 & \pm & 1.414 \\
\hline \multirow{2}{*}{ ANOVA } & F & \multirow{2}{*}{\multicolumn{3}{|c|}{$\begin{array}{l}0.354 \\
0.839\end{array}$}} & \multicolumn{3}{|c|}{19.097} \\
\hline & $\mathrm{P}$-value & & & & \multicolumn{3}{|c|}{$<0.001 *$} \\
\hline
\end{tabular}

Table (5) Comparison between the two studied groups according to age and after applying treatment

\begin{tabular}{lcccccc}
\hline & \multicolumn{3}{c}{ Age } \\
\cline { 2 - 7 } Hair After & \multicolumn{3}{c}{ Group A } & \multicolumn{3}{c}{ Group B } \\
\cline { 2 - 7 } & Mean & $\mathbf{\pm}$ & SD & Mean & \pm & SD \\
\hline Grade 0 & 26.000 & \pm & 0.000 & 30.000 & \pm & 1.581 \\
Grade I & 33.333 & \pm & 5.132 & 33.800 & \pm & 9.365 \\
Grade II & 31.364 & \pm & 4.342 & 34.000 & \pm & 1.000 \\
Grade III & 36.000 & \pm & 6.727 & 41.500 & \pm & 2.380 \\
\hline
\end{tabular}




\begin{tabular}{|c|c|c|c|c|c|c|c|}
\hline \multicolumn{8}{|c|}{ Table (5) Continue } \\
\hline Grade IV & & 34.000 & \pm & 3.018 & 42.667 & \pm & 1.155 \\
\hline ANOVA & $\begin{array}{c}\mathrm{F} \\
\text { P-value }\end{array}$ & & $\begin{array}{l}2.383 \\
0.074\end{array}$ & & & $\begin{array}{l}4.601 \\
0.013 *\end{array}$ & \\
\hline
\end{tabular}
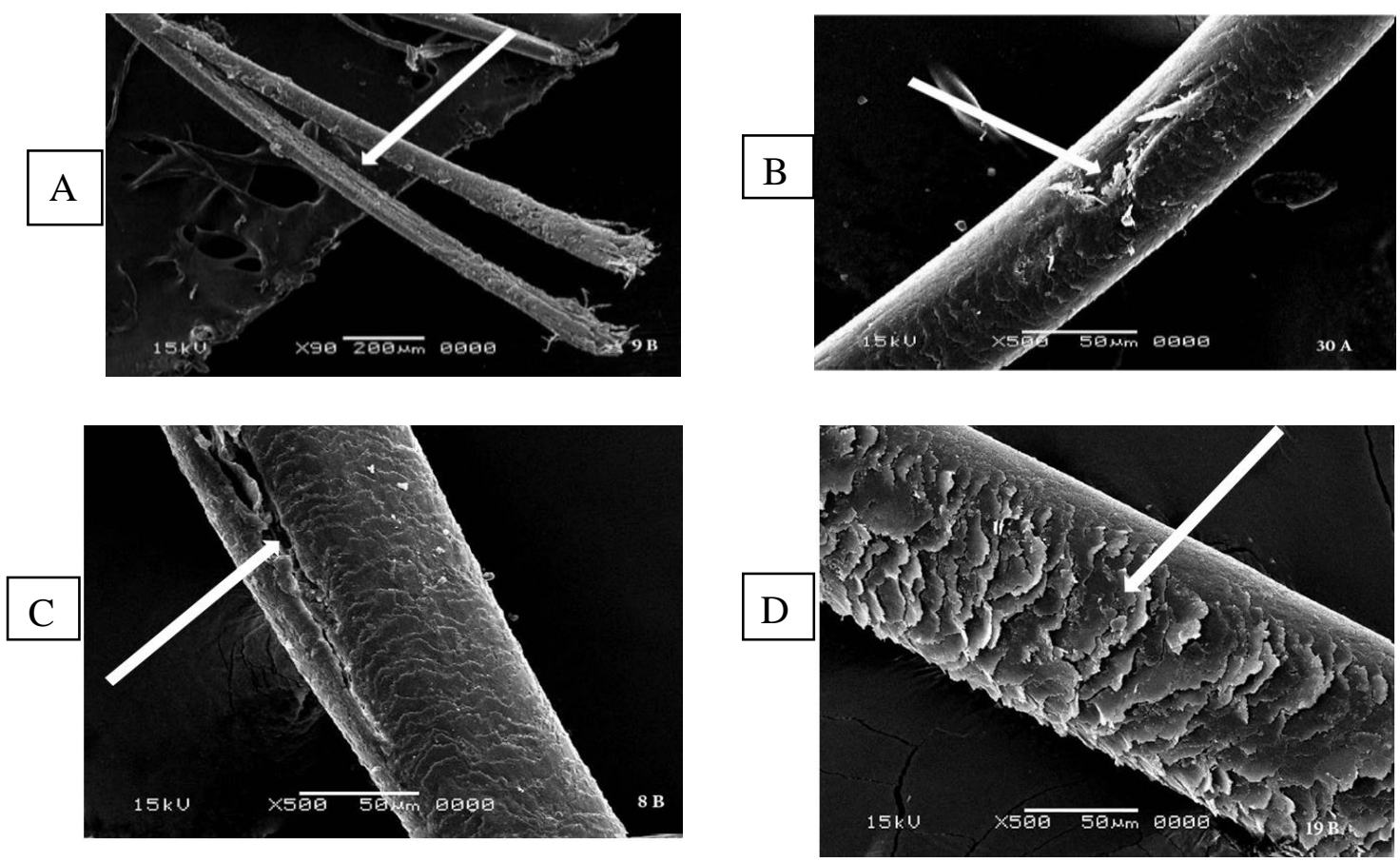

Fig (1) Hair straightener (Protein) effect on hair shaf

A: Irregular cuticle (arrow) grade 1 B: Wide cracking of the superficial layer of the cuticle(arrow) grade 2 C: Large hole arrow expose the cortex (arrow) grade 3 D: Depicting long splitting of the hair shaft showing the medulla (arrow) grade 4
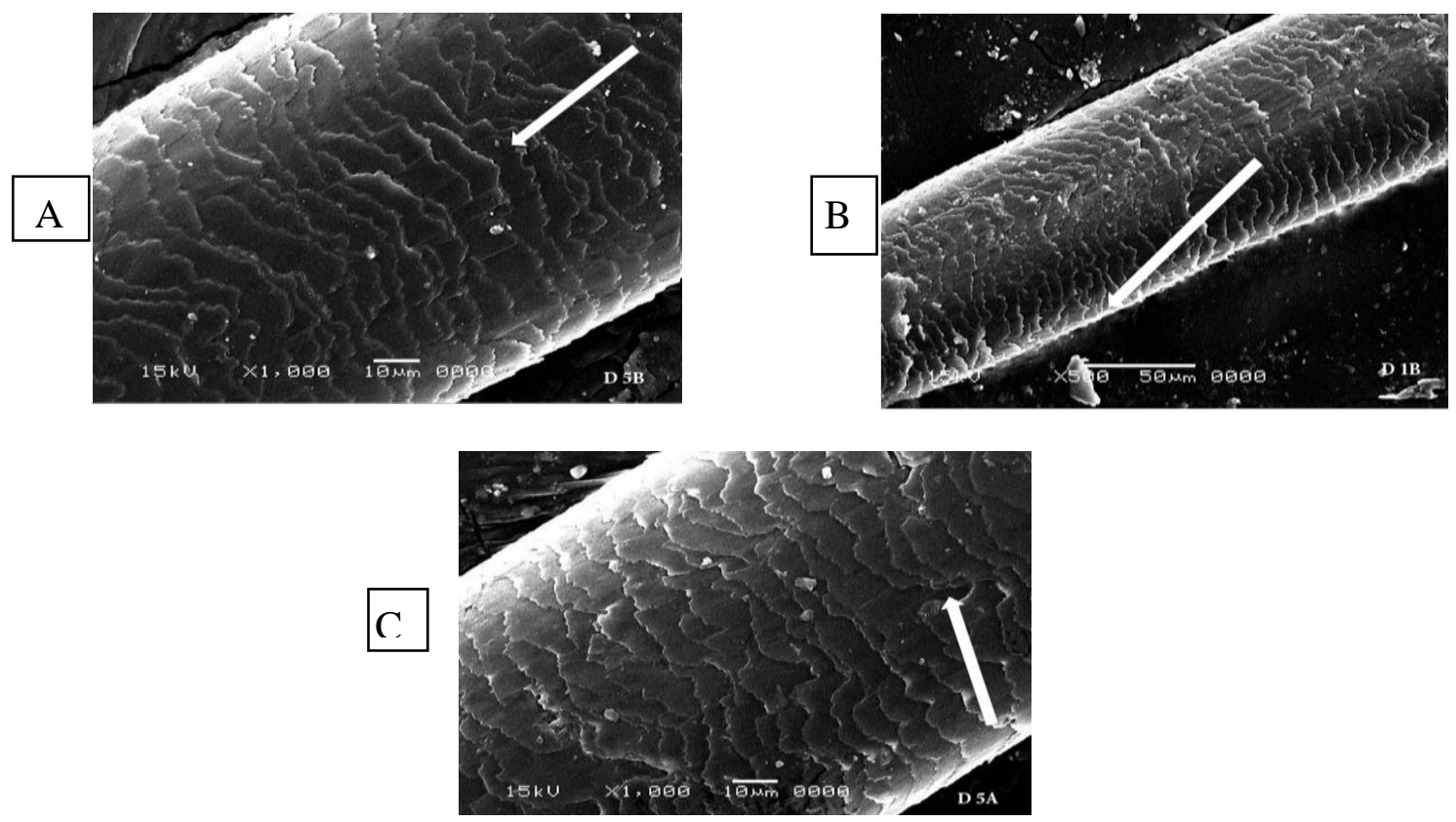

Fig (2) Dye effect on hair shaf

A: Some widening space ( arrow ) grade 0 B: Slight widening between the cuticle layers (arrow) grade 1 C: Hole in cuticle ( arrow ) grade 2 


\section{Discussion}

Our study Dyes has a great impact on the constitution of the hair, people who never used dyes or straighteners before have a more healthy hair than others. Permanent oxidative hair dye forms a combination of the oxidizing agents with ammonia hydroxide which can promote the opening of the cuticles. As a result, it allows the penetration of dye molecules into the cortex. Meanwhile, alkaline solution gives rise to the step height (height of one sheath relative to the next) of the hair shaft [6]. By examining the control group under EMS, $80 \%$ of them had intact hair with regularity of the cuticle and this proves the effect of dyes and straighteners on hair.

As regarding Compression between the two studied groups according to previous treatment. In group A: hair straightener, $57.14 \%$ of them experienced previous treatments. While in in group B: hair dye, $50 \%$ of them experienced previous treatment. There was no statistically significant difference between both groups regarding previous treatments $(\mathrm{P}=0.609)$.

As regarding Compression between the two studied groups according to scanning electronic microscope finding of hair. In group A: hair straightener, there was a statistically significant difference regarding EMS findings before and after treatment (P-value <0.001), before $\mathrm{ttt} 51 \%$ classified as group 0 , while after treatment $31 \%$ classified as Grade II. In group B: hair dye, there was no statistically significant difference regarding EMS findings before and after treatment $(\mathrm{P}=0.966)$. before $\mathrm{ttt}$, $43.64 \%$ were grade 0 , while after $\mathrm{ttt} 25.45 \%$ were Grade II. While the overall $\mathrm{P}$ value before and after treatment was $(\mathrm{P}<0.001)$.

In an expermental study, they concluded that, According to Kim et al, the hair damage grades consist of 5 grades. However, the damage shown in Kim et al. was extensive compared to this research. The hair samples of $\mathrm{H} 1$ to $\mathrm{H} 4$ were graded from Grade 0 to Grade 2. As each individual sample would have different degree of damages, the grades are added with minor and major. Minor grades indicated that the sample of selected class has less extensive damage features while Major grade indicated [6].

As regarding scanning electronic microscope finding in Group A according previous hair straightener apply. There was a statistically significant difference regarding EMS findings before and after treatment $(\mathrm{P}<0.001)$.

Also in analyzing scanning electronic microscope finding in Group B to previous dye apply. There was a statistically significant difference regarding EMS findings before and after treatment $(\mathrm{P}<0.014)$.

In Comparison between the three studied groups according to age, There was no statistically significant difference between them.

While Comparison between the two studied groups according to age and before applying treatment. In Group A, There was no statistically significant difference $(\mathrm{P}=0.839)$, while in Group B there was a statistically significant difference $(\mathrm{P}<0.001)$.

Also Comparison between the two studied groups according to age and after applying treatment, in Group
A, there was no statistically significant difference $(\mathrm{P}=0.074)$, in Group $\mathrm{B}$, there was a statistically significant difference $(\mathrm{P}=0.013)$.

These results showed that, the use of hair straightener leads to very significant damage to the layers of hair especially if the individual is frequent compared to using the dye that is considered less harmful.

The damage that occurs as a result of the use of hair straightener begins from the outer layer of the hair shaft ( cuticle ) and extends to inner layers ( cortex ) which leads to the irregularity of cuticle and develops into very large damage until the distraction of the inner layer and the hair shaft his broken.

In the study of Kaliyadan et al., [2], to evaluate Scanning Electron Microscopy Study of Hair Shaft Damage Secondary to Cosmetic Treatments of the Hair. They concluded that, Twenty-five female subjects voluntarily participated in the study which was done to assess hair shaft damage in those who frequently use bleaching, dyeing, and straightening treatments. None of the patients in the study group were using coconut oil over the scalp. SEM was used to assess the hair shaft and visualize the extent of damage in the study group (those frequently using hair treatments) and control group (those regularly using hair oil and no other treatment). Of the total, $42.1 \%$ of subjects in the study group had Grade 2 changes, and $15.7 \%$ had Grade 3 changes, whereas $33.3 \%$ of the control group had Grade 1 changes. No subject in the control group had Grade 2 or higher changes. The results from this small study indicate that treatments such as bleaching, dyeing, and straightening can have an adverse effect on the hair shaft.

In the study of Ali et al., [7], they also documented changes in the hair such as breaking off or lifting up of cuticular scales, roughness in hair surface, tearing, and fragmentation of cuticle in hair samples that have undergone chemical (bleaching, coloring, and waving) and physical treatments (hot straightening).

Another experimental in vitro study done by Lee et al ., [8], has demonstrated that hair that was dried using a hair dryer showed more damage of hair surfaces and hair surfaces tend to become more damaged as temperatures increase.

Frequent use of chemical agents is considered to be a major cause of damage to the hair shaft which can produce characteristic changes visible on SEM [9].

in the study of Davis et al., [6], they concluded that, SEM examinations have concluded that there were more damages found on hair cuticles than other parts. This is due to the presence of hair dye, although thick medulla in the dyed hair sample showed a negative effect (unchanged). The colour of the hair changed due to the penetration of hair dye molecule to the cortex of the hair. Conclusively, hair dye is proven to modify the structure of outer and inner layer of the hair.

From all the aforementioned data we can conclude that, EMS is a useful tool in assessing hair changes related to use of chemical agents. In our study, the use of hair straightener leads to very significant damage to the layers of hair especially if the individual is frequent 
compared to using the dye that is considered less harmful.

The damage that occurs as a result of the use of hair straightener begins from the outer layer of the hair shaft ( cuticle ) and extends to inner layers ( cortex ) which leads to the irregularity of cuticle and develops into very large damage until the distraction of the inner layer and the hair shaft his broken. Further work-up should be done on the role of EMS in assessing such hair changes including bigger sample size.

\section{References}

[1] M.A.Aglan, G.N.(Mansour. Hair straightening products and the risk of occupational formaldehyde exposure in hairstylists. Drug and chemical toxicology, PP.1-8,2018.

[2] F.Kaliyadan, B.B.Gosai, W. N.Al Melhim. Scanning Electron Microscopy Study of Hair Shaft Damage Secondary to Cosmetic Treatments of the Hair. International J., trichology, Vol.8,PP. 9498,2016.

[3] A.L.Miranda-Vilela, A.J.Botelho, L.A.Muehlmann. An overview of chemical straightening of human hair: technical aspects, potential risks to hair fibre and health and legal issues. International J., Cosmetic Science, Vol. 36,PP. 2-11. ,2014.

[4] L.S.Abraham, A.M. Moreira, L.H. De Moura. Tratamentos estéticos e cuidados dos cabelos: uma visão médica (parte 2). Surgical \& Cosmetic Dermatology, Vol.1,PP. 178-185,2009.

[5] M.M.Baum, J.M.Baum, Keratin-based hair straightening formulations, methods and systems. Google Patents, 2019.

[6] M.G.Davis, J.H.Thomas, S.van de Velde. novel cosmetic approach to treat thinning hair. $\mathrm{Br} \mathrm{J}$ Dermatol, Vol.165(Suppl 3),PP.24-30,2011.

[7] N.Ali, R.Zohra, S.Qader, M.Mumtaz. Scanning electron microscopy analysis of hair index on $\mathrm{K}$ arachi's population for social and professional appearance enhancement. International J., cosmetic science, Vol.37,PP. 312-320,2015.

[8] Y.Lee, Y.D. Kim, H.J.Hyun. Hair shaft damage from heat and drying time of hair dryer. Ann Dermatol, Vol.23,PP. 455-62,2011.

[9] Y.Lee, Y.D.Kim, L.Q. Pi. Comparison of hair shaft damage after chemical treatment in Asian, White European, and African hair. Int J Dermatol, Vol. 53,PP. 1103-10,2014. 